\title{
Achilles Tendon Thickness and Stiffness Evaluation with Shear-Wave Elastography in Hemodialysis Patients
}

\author{
Azad Hekimoglu ${ }^{1,}{ }^{*}$, Aynur Turan ${ }^{1}$, Begum Demirler Simsir ${ }^{1}$, Hasan Ali Durmaz ${ }^{1}$, Mehmet Deniz Ayli ${ }^{2}$ \\ and Baki Hekimoglu ${ }^{1}$
}

${ }^{1}$ Department of Radiology, Diskapi Yildirim Beyazit Training and Research Hospital, Ankara, Turkey

${ }^{2}$ Department of Nephrology, Diskapi Yildirim Beyazit Training and Research Hospital, Ankara, Turkey

"Corresponding author: Department of Radiology, Diskapi Yildirim Beyazit Training and Research Hospital, Ankara, Turkey, Tel: +90-5067559485, Email: azadjafarov@mynet.com

Received 2018 January 14; Revised 2019 March 13; Accepted 2019 March 19

\begin{abstract}
Background: Changes in tendon structure are expected in chronic renal failure (CRF) due to metabolic alterations. Shear-wave elastography (SWE) is a new elastography technique that determines soft tissue elasticity noninvasively. SWE may determine early tendon degeneration due to CRF.

Objectives: We aim to determine Achilles tendon thickness and elasticity in CRF patients undergoing hemodialysis with B-mode and SWE ultrasonography (US).

Patients and Methods: Thirty-four (23 male, 11 female) patients with CRF and 32 healthy individuals (24 male, eight female) were included in the study. Initially both Achilles tendons of patients were evaluated for structural abnormalities or focal lesions then tendon thickness was measured with B-mode US. Tendon stiffness was measured by SWE in kilopascal (kPa) units.

Results: Mean Achilles tendon thickness in the patient group was significantly lower than the control group ( $4.16 \pm 0.59 \mathrm{~mm}$ vs. $4.78 \pm 0.61 \mathrm{~mm}, \mathrm{P}<0.001)$. The mean elasticity scores in the patient group was $26.00 \pm 9.74 \mathrm{kPa}$ and $24.64 \pm 6.64 \mathrm{kPa}$ in the control group which was not statistically significant.

Conclusion: Achilles tendon is thinner in chronic renal failure patients compared to the control group. However, there was no significant difference between the groups in stiffness values of tendons measured by SWE.
\end{abstract}

Keywords: Achilles Tendon, Chronic Kidney Failure, Elastography, Hemodialysis

\section{Background}

Spontaneous tendon rupture is a rare injury during activity. It has been frequently associated with chronic metabolic diseases such as chronic renal failure (CRF), diabetes mellitus, systemic lupus erythematosis, rheumatoid arthritis, gout and obesity (1). Hyperparathyroidism and metabolic acidosis in CRF patients are known to be risk factors for tendon degeneration (2). In CRF patients, secondary hyperparathyroidism, osteomalacia, osteoporosis, a dynamic bone disease, soft tissue and vascular calcifications could be seen due to renal osteodystrophy. Some musculoskeletal disorders such as amyloid and crystal deposition, destructive spondyloarthropathy, avascular necrosis, and spontaneous tendon rupture could also be seen in these patients (3).

Sonoelastography (SE) is a recent ultrasound technology that provides information about elasticity and stiffness of different tissues or lesions (4). In this method, the pressure applied to the tissue provides information about the physical and mechanical characteristics of the tissue such as elasticity and hardness. These characteristics help to differentiate tissue types as well as different pathologic conditions of the same tissue (5). Recently, SE has been used to evaluate the breast, thyroid, muscle, and abdominal solid organ diseases (6-9). Previous studies have shown that SE is efficient for demonstrating alterations of Achilles tendon (10).

Shear-wave elastography (SWE) is a noninvasive elastography technique that measures soft tissue elasticity quantitatively in kilopascal units, by sending acoustic impulse to the tissue without applying pressure unlike other SE techniques (11).

\section{Objectives}

The purpose of the current study was to evaluate Achilles tendon thickness with B-mode ultrasonography 
(US) and stiffness using SWE technique in CRF patients undergoing hemodialysis.

\section{Patients and Methods}

\subsection{Radiologic Assessments}

The study was designed prospectively and approved by the research ethics committee. Signed consent forms in accordance with Helsinki declaration were obtained from patients and healthy individuals.

Thirty-four CRF patients (23 male, 11 female) undergoing hemodialysis in our hospital and 32 healthy individuals (24 male, eight female) were included in the study. The mean hemodialysis duration was 3 years ( 1 month 20 years). CRF patients that had at least a one-month hemodialysis duration were included in the study. The patients with previous sports or trauma injury, lower extremity osteoarthritis, and patients who had undergone surgery or treatment, such as knee prosthesis surgery, were also excluded. The control group was formed from randomly selected healthy volunteers who were attendants of patients presented to the US unit.

\subsection{Ultrasonography Technique}

During the evaluation of Achilles tendon, the patients were in relaxed prone position with their feet hanging freely over the edge of the table without flexion or extension (12). As Achilles tendon is located superficially, GE Healthcare Logiq E9 device and $9 \mathrm{MHz}$ frequency linear probe was used in the study. After positioning of the probe, the tendon was easily identified by following the muscle tissue to the calcaneal insertion site (13). The measurements were done by one radiologist $(\mathrm{AH})$ with more than 5 years of experience in US. Each measurement was repeated three times and the mean was calculated.

Initially, both Achilles tendons were examined in transverse and longitudinal planes from calf muscles to the calcaneal insertion in terms of homogeneity, thickness, and structural abnormality. Achilles tendon thickness was measured from the distal part at the level of medial malleolus as mentioned in previous studies (14). The region of interest (ROI) was placed in the middle of the tendon and automatic stiffness was calculated in kilopascal units (Figure 1). SWE method is different from other elastographic methods for its direct measurement of stiffness of ROI without applying any pressure.

\subsection{Statistical Analysis}

Data analysis was performed using SPSS for Windows, version 11.5 (SPSS Inc., Chicago, IL, United States). Whether the distributions of continuous variables were normal or not was determined by Shapiro Wilk test. Continuous variables were shown as mean \pm standard deviation (SD) or median (min - max), where applicable. Number of cases and percentages were used for nominal data. The differences in normally distributed data between control and case groups were compared by Student's $t$ test, otherwise, Mann Whitney U test was applied for the variables which were far from normal distribution. Nominal data were analyzed by Pearson's Chi-square test. Degrees of association between continuous variables were evaluated by Spearman's rank correlation analyses. A P value less than 0.05 was considered statistically significant. The correlation coefficients of age and thickness and elasticity were evaluated by Pearson correlation test.

\section{Results}

The mean age of the patient group was $54 \pm 17$ (range 24 - 85) and for the control group, it was $42 \pm 9$ (range 20 56) $(\mathrm{P}<0.05)$. Male/female ratio of both groups were simi$\operatorname{lar}(\mathrm{P}=0.510)$ (Table 1$)$. The demographic data of the study group, the thickness and stiffness of Achilles tendon are presented in Table 1. The mean Achilles tendon thickness in the patient group was $4.14 \pm 0.62 \mathrm{~mm}$ on the right side and $4.19 \pm 0.59 \mathrm{~mm}$ on the left side (mean of both sides, $4.16 \pm 0.59 \mathrm{~mm}$ ). The control group had a tendon thickness of $4.79 \pm 0.62 \mathrm{~mm}$ on the right side, $4.77 \pm 0.63 \mathrm{~mm}$ on the left side (mean of both sides, $4.78 \pm 0.61 \mathrm{~mm}$ ). When we compared the results, the thickness of Achilles tendon was significantly lower in the patient group $(\mathrm{P}<0.001)$ (Figure 2). The mean elasticity scores of Achilles tendons in the patient group was $27.10 \pm 10.83 \mathrm{kPa}$ on the right side, and $24.90 \pm 10.39 \mathrm{kPa}$ on the left side (mean of both sides, $26.00 \pm 9.74 \mathrm{kPa}$ ). Whereas, in the control group values were $24.62 \pm 7.40,24.66 \pm 7.28$, and $24.64 \pm 6.64$ for the right, left and mean of both sides, respectively. There was no statistically significant difference in stiffness values between the two groups ( $\mathrm{P}>0.05$ ) (Figure 3).

There was no statistically significant difference between the duration of hemodialysis and right, left and mean stiffness values $(\mathrm{P}>0.05)$ (Table 2$)$. There were also no correlations between age and tendon thickness and elasticity both in the control and patient groups. Both tendon thickness and elasticity were mildly correlated with age $(r=0.27$ and $\mathrm{P}=0.03, \mathrm{r}=0.34$ and $\mathrm{P}=0.007$, respectively).

\section{Discussion}

Achilles tendon is the strongest, largest, and thickest tendon in the human body consisting of type I collagen 


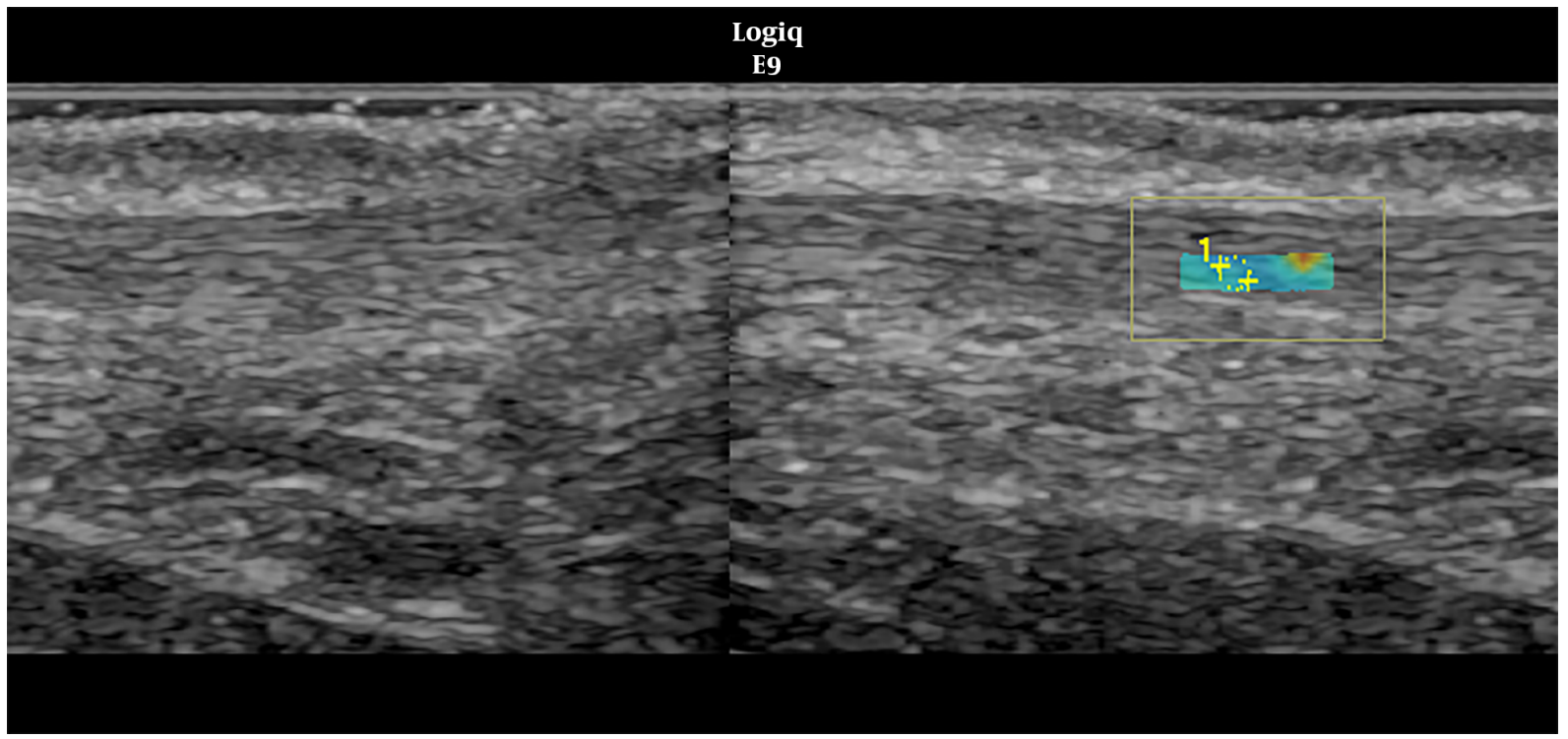

Figure 1. A region of interest (ROI) was placed in the central area of the Achilles tendon and tissue elasticity was given automatically by machine in kiloPascal units

\begin{tabular}{|c|c|c|c|}
\hline & Controls $(\mathrm{N}=32)$ & $\mathrm{CKD}(\mathrm{N}=32)$ & Pvalue \\
\hline Age, $y$ & $42.4 \pm 9.0$ & $54.7 \pm 17.7$ & $<0.001$ \\
\hline Gender & & & 0.510 \\
\hline Male & $24(75.0)$ & $23(67.6)$ & \\
\hline Female & $8(25.0)$ & $11(32.4)$ & \\
\hline $\begin{array}{l}\text { Duration of } \\
\text { hemodialysis, y }\end{array}$ & - & $\begin{array}{c}3 \text { (1 month - } 20 \\
\text { years) }\end{array}$ & - \\
\hline \multicolumn{4}{|c|}{$\begin{array}{l}\text { Achilles thickness, } \\
\text { mm }\end{array}$} \\
\hline Right & $4.79 \pm 0.62$ & $4.14 \pm 0.62$ & $<0.001$ \\
\hline Left & $4.77 \pm 0.63$ & $4.19 \pm 0.59$ & $<0.001$ \\
\hline Mean & $4.78 \pm 0.61$ & $4.16 \pm 0.59$ & $<0.001$ \\
\hline \multicolumn{4}{|l|}{ Elastography, kPa } \\
\hline Right & $24.62 \pm 7.40$ & $27.10 \pm 10.83$ & 0.362 \\
\hline Left & $24.66 \pm 7.28$ & $24.90 \pm 10.39$ & 0.893 \\
\hline Mean & $24.64 \pm 6.64$ & $26.00 \pm 9.74$ & 0.594 \\
\hline
\end{tabular}

Abbreviations: CKD, chronic kidney disease; kPa, kiloPascal; SD, standard deviation; y, year

${ }^{\mathrm{a}}$ Values are expressed as No. (\%) or mean \pm SD.

(15). The hard structure of a healthy tendon can be affected by disease, toxin, and drugs that cause collagen defect and the tendon becomes soft and weak (16).

In CRF patients, malnutrition, accumulation of uremic toxins, secondary hyperparathyroidism, metabolic acidosis and deposition of amyloid (especially beta 2 -

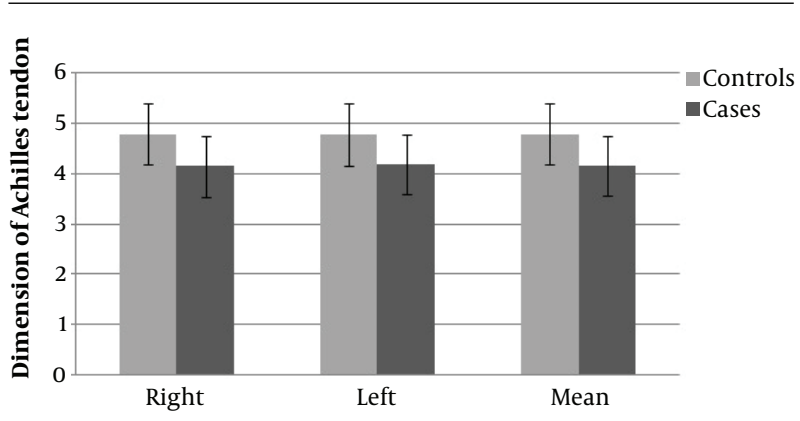

Figure 2. Analysis of Achilles tendon thickness in patients with chronic kidney disease (CKD) and the control group

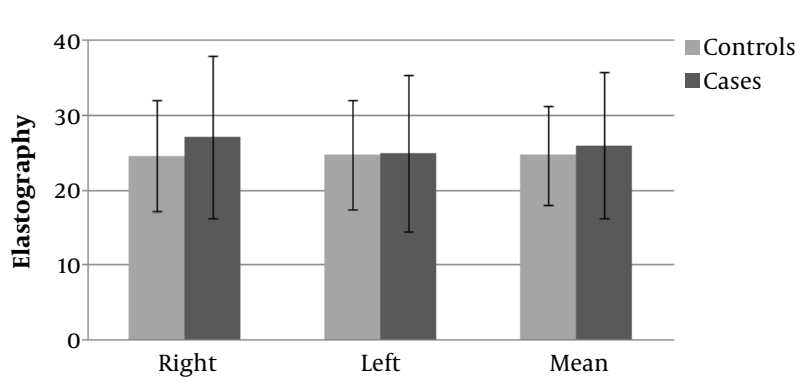

Figure 3. Analysis of elastographic stiffness values of Achilles tendon in patients with chronic kidney disease (CKD) and the control group

microglobulin) was reported as a cause of weakening of the tendon and also a risk factor for tendon rupture $(17,18)$. 
Table 2. Degrees of Associations Between Duration of Hemodialysis and Elastography Measurements

\begin{tabular}{lcc}
\hline Elastography & Correlation coefficient & Pvalue \\
\hline Right & 0.130 & 0.464 \\
Left & 0.079 & 0.657 \\
Mean & 0.111 & 0.532 \\
\hline
\end{tabular}

The tendon could be evaluated by B-mode sonography (19). However, B-mode sonography has limitations in differentiating early changes in the tendon as early alterations usually cannot be distinguished from the normal tendon (20). Magnetic resonance imaging (MRI) is the gold-standard imaging technique for morphological analysis of tendons however, neither US nor MRI can assess the viscoelasticity and early changes of tendons (21). SE is a more sensitive new technique for evaluation of tendon alterations $(22,23)$.

There are different SE methods such as compression elastography, shear-wave elastography and transient elastography. In this study, SWE technique was used. SWE was combined with conventional ultrasonographic linear transducer. In this technique, the velocity of the shear waves generated by ultrasound pulses that are sent perpendicular to the tissue, and the elasticity characteristics of the tissue are determined. Increased elasticity results in increased velocity. The quantitative measurement units are kilopascals or centimeters per second $(24,25)$. The shear wave velocity can be measured and used to evaluate the elasticity of the tissue. The advantages of this method are lack of manual compression requirement (22), and quantitative measurement. The limited ROI size and shape (only circle or box) are the limitations (25).

Several elastography studies confirm that a normal Achilles tendon is hard and conditions such as tendinopathy and tendon rupture cause decrease in stiffness and the tendon becomes markedly soft $(8,12,25)$. Aubry et al. showed that in SWE technique, the mean velocity was decreased in the mid portion of Achilles tendon, meaning the tendon was softer in patients with tendinopathy confirmed with US (26). Their study showed that softening assessed by SWE is highly specific for tendinopathy but sensitivity was relatively low. The elasticity properties of Achilles tendon might improve the diagnosis of early tendon pathology.

There are SE studies investigating the effect of rheumatological diseases, aging and various pathologies on Achilles tendon $(14,27)$. In a study carried out by Teber et al. on the quadriceps tendons of 53 patients of whom the mean hemodialysis duration was 7.6 years, a decrease in the stiffness and heterogeneity in the color mapping of the tendons of patients compared to those of the healthy control group were recorded (28). In contrary with the study conducted by Teber et al. (28), we found no significant difference between the stiffness values of the patient and the control groups. The inconsistency between the results of the two studies may be caused by adoption of different techniques and/or the different mean dialysis durations of the two study populations. Teber et al. used strain elastography technique whereas we used SWE which enables quantitative measurement. It has been previously shown that tendon damage increases as duration of dialysis increases $(28,29)$. The mean dialysis duration of the population of the current study was shorter than that of the other study. It is within the bound of possibilities that we might have made SWE assessments early before the development of tendon alterations.

These results could also be due to the small sample size and the difference in age between the patient and control group in our study. The mean age of CRF patients was 54 \pm 17 ; whereas, the mean age of the control group was 42 \pm 9 . Previously, Turan et al. (30) reported that tendon stiffness increased in elderly subjects. In this study, the higher mean age of CRF patients compared to the control group may be the reason for a relative increase in stiffness in these patients.

The results of this study showed that Achilles tendon was significantly thinner in CRF patients $(\mathrm{P}<0.001)$. This result was opposed by Hussein et al., who showed that the middle and distal one third thicknesses of Achilles tendon was increased and they found positive correlation between the duration of dialysis and tendon thickness (29). Similarly, Kerimoglu et al. reported that quadriceps and Achilles tendon and plantar fascia was thicker secondary to amyloid accumulation, particularly in patients whose hemodialysis duration was over 10 years. Enthesal sites were evaluated due to significant periarticular amyloid accumulation. It was stated that tendon measurements were made at the thickest site (31). Whereas, in the current study, the measurements were taken at the middle one third of the tendon. The differences in results may be due to different sites of measurement. However, there is an agreement with Teber et al. They found that quadriceps tendon was thinner in hemodialysis patients compared to the control group (28).

We acknowledge the following limitations. First, the small sample size and the difference in age between the patient and control group. Taking into account that stiffness could also be affected by aging, the mean age of compared groups should be similar. The other limitation was the duration of hemodialysis, which was very short in some patients. Another limitation of this study was the evaluation of tendon at its middle one third portion. Evalua- 
tion of the distal part could also give useful information. Another limitation was the small-sized and limited ROI in SWE, which restricts evaluation of the tendon as a whole contrary to strain elastography. Finally, the anisotropic nature of Achilles tendon was also a limitation. In order to overcome anisotropy, the transducer should be positioned as perpendicular as possible to the tendon but it is not successfully achieved in all cases.

In conclusion, despite tendon evaluation with strain elastography in hemodialysis patients was reported before, to our knowledge no studies were performed using the shear-wave technique. The current study does not reveal any significant elastography results in the mid portion of Achilles tendons in CRF patients. However, it should be emphasized that further studies with larger patient groups is necessary.

\section{Footnotes}

Authors' Contributions: Study concept and design: Azad Hekimoglu and Aynur Turan; acquisition of data: Azad Hekimoglu and Aynur Turan; analysis and interpretation of data: Begum Demirler Simsir and Aynur Turan; drafting of the manuscript: Azad Hekimoglu, Begum Demirler Simsir and Hasan Ali Durmaz; critical revision of the manuscript for important intellectual content: Baki Hekimoglu and Mehmet Deniz Ayli; statistical analysis: Azad Hekimoglu, Begum Demirler Simsir and Hasan Ali Durmaz; study supervision: Baki Hekimoglu and Mehmet Deniz Ayli

Conflict of Interests: The authors declare that they have no conflict of interests.

Ethical Considerations: All procedures performed in studies involving human participants were in accordance with the ethical standards of the institutional and/or national research committee and with the 1964 Helsinki declaration and its later amendments or comparable ethical standards.

Financial Disclosure: The authors have no financial interests or financial conflicts.

Funding/Support: Financial or material supports were not received for this study.

\section{References}

1. Ilan DI, Tejwani N, Keschner M, Leibman M. Quadriceps tendon rupture. J Am Acad Orthop Surg. 2003;11(3):192-200. [PubMed: 12828449].

2. Kazimoglu C, Yagdi S, Karapinar H, Sener M. [Bilateral quadriceps tendon rupture and coexistent femoral neck fracture in a patient with chronic renal failure]. Acta Orthop Traumatol Turc. 2007;41:393-6. Turkish.
3. Bardin T. Musculoskeletal manifestations of chronic renal failure. Curr Opin Rheumatol. 2003;15(1):48-54. doi: 10.1097/00002281200301000-00009. [PubMed: 12496510].

4. Garra BS. Elastography: Current status, future prospects, and making it work for you. Ultrasound Q. 2011;27(3):177-86. doi: 10.1097/RUQ.0b013e31822a2138. [PubMed: 21873855].

5. Alam F, Naito K, Horiguchi J, Fukuda H, Tachikake T, Ito K. Accuracy of sonographic elastography in the differential diagnosis of enlarged cervical lymph nodes: comparison with conventional B-mode sonography. AJR Am J Roentgenol. 2008;191(2):604-10. doi: 10.2214/AJR.07.3401. [PubMed: 18647939].

6. Ghajarzadeh M, Sodagari F, Shakiba M. Diagnostic accuracy of sonoelastography in detecting malignant thyroid nodules: A systematic review and meta-analysis. AJR Am J Roentgenol. 2014;202(4):W379-89. doi: 10.2214/AJR.12.9785. [PubMed: 24660737].

7. Sandulescu L, Rogoveanu I, Gheonea IA, Cazacu S, Saftoiu A. Realtime elastography applications in liver pathology between expectations and results. J Gastrointestin Liver Dis. 2013;22(2):221-7. [PubMed: 23799224].

8. Botar Jid C, Vasilescu D, Damian L, Dumitriu D, Ciurea A, Dudea SM. Musculoskeletal sonoelastography. Pictorial essay. Med Ultrason. 2012;14(3):239-45. [PubMed: 22957331].

9. Grajo JR, Barr RG. Strain elastography for prediction of breast cancer tumor grades. J Ultrasound Med. 2014;33(1):129-34. doi: 10.7863/ultra.33.1.129. [PubMed: 24371107].

10. De Zordo T, Chhem R, Smekal V, Feuchtner G, Reindl M, Fink C, et al. Real-time sonoelastography: Findings in patients with symptomatic achilles tendons and comparison to healthy volunteers. Ultraschall Med. 2010;31(4):394-400. doi: 10.1055/s-0028-1109809. [PubMed: 19946833].

11. Arda K, Ciledag N, Aktas E, Aribas BK, Kose K. Quantitative assessment of normal soft-tissue elasticity using shear-wave ultrasound elastography. AJR Am J Roentgenol. 2011;197(3):532-6. doi: 10.2214/AJR.10.5449. [PubMed: 21862792].

12. Palle L, Reddy MB, Reddy KJ, Kumari MV. Technical note: Real-time sonoelastography evaluation of Achilles tendon. Indian J Radiol Imaging. 2011;21(4):267-9. doi: 10.4103/0971-3026.90685. [PubMed: 22223937]. [PubMed Central: PMC3249940].

13. Kaplan PA, Matamoros A, Anderson JC. Sonography of the musculoskeletal system. Am J Roentgenol. 1990;155(2):237-45. doi: 10.2214/ajr.155.2.2115246. [PubMed: 2115246].

14. Shiota E, Tsuchiya K, Yamaoka K, Kawano O. Spontaneous major tendon ruptures in patients receiving long-term hemodialysis. Clin Orthop Relat Res. 2002;(394):236-42. doi: 10.1097/00003086-20020100000028. [PubMed: 11795739].

15. O'Brien M. The anatomy of the Achilles tendon. Foot Ankle Clin. 2005;10(2):225-38. doi:10.1016/j.fcl.2005.01.011. [PubMed: 15922915].

16. Dillehay GL, Deschler T, Rogers LF, Neiman HL, Hendrix RW. The ultrasonographic characterization of tendons. Invest $\mathrm{Ra}$ diol. 1984;19(4):338-41. doi: 10.1097/00004424-198407000-00020. [PubMed: 6384128].

17. Kurer MH, Baillod RA, Madgwick JC. Musculoskeletal manifestations of amyloidosis. A review of 83 patients on haemodialysis for at least 10 years. J Bone Joint Surg Brit. 1991;73-B(2):271-6. doi: 10.1302/0301620x.73b2.2005153.

18. Thaunat M, Gaudin P, Naret C, Beaufils P, Thaunat O. Role of secondary hyperparathyroidism in spontaneous rupture of the quadriceps tendon complicating chronic renal failure. Rheumatology (Oxford). 2006;45(2):234-5. doi: 10.1093/rheumatology/kei022. [PubMed: 16332956].

19. Shah M, Jooma N. Simultaneous bilateral quadriceps tendon rupture while playing basketball. Br J Sports Med. 2002;36(2):152-3. discussion 153. doi: 10.1136/bjsm.36.2.152. [PubMed: 11916903]. [PubMed Central: PMC1724489].

20. Lotem M, Robson MD, Rosenfeld JB. Spontaneous rupture of the quadriceps tendon in patients on chronic haemodialysis. Ann Rheum 
Dis. 1974;33(5):428-9. doi: 10.1136/ard.33.5.428. [PubMed: 4424440]. [PubMed Central: PMC1006299].

21. Aubry S, Risson JR, Kastler A, Barbier-Brion B, Siliman G, Runge M, et al. Biomechanical properties of the calcaneal tendon in vivo assessed by transient shear wave elastography. Skeletal Radiol. 2013;42(8):1143-50. doi:10.1007/s00256-013-1649-9. [PubMed: 23708047].

22. Klauser AS, Faschingbauer R, Jaschke WR. Is sonoelastography of value in assessing tendons? Semin Musculoskelet Radiol. 2010;14(3):323-33. doi: 10.1055/s-0030-1254521. [PubMed: 20539957].

23. Sharma P, Maffulli N. Biology of tendon injury: Healing, modeling and remodeling. J Musculoskelet Neuronal Interact. 2006;6(2):181-90. [PubMed: 16849830].

24. Dudea SM, Botar-Jid C. Ultrasound elastography in thyroid disease. Med Ultrason. 2015;17(1):74-96. doi: 10.11152/mu.2013.2066.171.smd. [PubMed: 25745661].

25. Klauser AS, Miyamoto H, Bellmann-Weiler R, Feuchtner GM, Wick MC, Jaschke WR. Sonoelastography: Musculoskeletal applications. Radiology. 2014;272(3):622-33. doi: 10.1148/radiol.14121765. [PubMed: 25153273].

26. Aubry S, Nueffer JP, Tanter M, Becce F, Vidal C, Michel F. Viscoelasticity in Achilles tendonopathy: Quantitative assessment by using real-time shear-wave elastography. Radiology. 2015;274(3):821-9. doi: 10.1148/radiol.14140434. [PubMed: 25329764].

27. Turan A, Teber MA, Yakut ZI, Unlu HA, Hekimoglu B. Sonoelastographic assessment of the age-related changes of the Achilles tendon. Med Ultrason. 2015;17(1):58-61. doi: 10.11152/mu.2013.2066.171.ayt. [PubMed: 25745659].

28. Teber MA, Ogur T, Bozkurt A, Er B, Turan A, Gulbay M, et al. Realtime sonoelastography of the quadriceps tendon in patients undergoing chronic hemodialysis. J Ultrasound Med. 2015;34(4):671-7. doi 10.7863/ultra.34.4.671. [PubMed: 25792583].

29. Hussein DA, El-Azizi NO, Abdel Meged AH, Al-Hoseiny SA, Hamada AM, Sabry MH. Ultrasonographic tendon alteration in relation to parathyroid dysfunction in chronic hemodialysis patients. Clin Med Insights Arthritis Musculoskelet Disord. 2015;8:9-14. doi: 10.4137/CMAMD.S20887. [PubMed: 25674023]. [PubMed Central: PMC4315125].

30. Turan A, Tufan A, Mercan R, Teber MA, Tezcan ME, Bitik B, et al. Realtime sonoelastography of Achilles tendon in patients with ankylosing spondylitis. Skeletal Radiol. 2013;42(8):1113-8. doi: 10.1007/s00256013-1637-0. [PubMed: 23685710].

31. Kerimoglu U, Hayran M, Ergen FB, Kirkpantur A, Turgan C. Sonographic evaluation of entheseal sites of the lower extremity in patients undergoing hemodialysis. J Clin Ultrasound. 2007;35(8):417-23. doi: 10.1002/jcu.20411. [PubMed: 17663458]. 